\section{Occupational asthma in a pharmaceutical worker exposed to hydralazine}

\author{
B Perrin, J-L Malo, A Cartier, S Evans, \\ J Dolovich
}

\begin{abstract}
A pharmaceutical worker developed asthma when exposed to hydralazine, an antihypertensive drug. The diagnosis of occupational asthma was supported by specific inhalation challenges, which produced a late asthmatic reaction and an increase in bronchial responsiveness. No evidence of an IgE or an IgG dependent mechanism could be found.
\end{abstract}

Occupational asthma due to pharmaceutical products in powder form among pharmacists, nurses, doctors, and workers at drug manufacturing plants has been described frequently. Several agents have been incriminated, as reviewed elsewhere. ${ }^{12}$ To the best of our knowledge, the antihypertensive drug hydralazine has never been linked to occupational asthma.

\section{Case report}

A 35 year old man had worked for four years as an operator at a pharmaceutical plant. Two years after beginning this work he noticed sneezing, dyspnoea, and wheezing on exposure to psyllium. Occupational asthma due to psyllium was excluded on the basis of negative results from an inhalation challenge test, in which the man was asked to tip psyllium from one tray to another in a challenge room. ${ }^{12} \mathrm{He}$ showed no immediate skin reactivity to psyllium and the levels of specific IgE antibodies were normal (in contrast to occupational asthma due to psyllium in our experience ${ }^{34}$ ). The subject also reported having symptoms of seasonal rhinitis since he was 18 , which had become perennial in the preceding two years. The finding of bronchial hyperresponsiveness with a provocation concentration of methacholine causing a $20 \%$ fall in FEV $\left(\mathrm{PC}_{20}\right)$ of $1.5 \mathrm{mg} / \mathrm{ml}^{5}$ led to a diagnosis of asthma in 1985 .

The subject moved to another pharmaceutical company in 1985 , where he also worked as an operator and where his exposure to hydralazine began, four years before his referral in 1989. In the preceding year he had noticed symptoms of sneezing, dyspnoea, and wheezing during the second day that hydralazine was being prepared. The symptoms appeared progressively and persisted for the four or five days when hydralazine was being made. He improved once the preparation of hydralazine had ended. Hydralazine was prepared every one to two months for four to five days. Skinprick tests with 15 common inhalant allergens and hydralazine diluted in phosphate buffered saline in concentrations of 0.1 and $1 \mathrm{mg} / \mathrm{ml}$ gave negative results. The total serum IgE level was $96 \mathrm{IU} / 1$ (normal). Tests for serum IgE antibodies to Dermatophagoides farinae, cat danders, and ragweed and grass pollens gave negative results.

Specific inhalation challenges were performed after four days away from work. The results are illustrated in the figure. On the first day the patient was exposed to lactose for 15 minutes with a new aerosolisation device, which keeps the concentration of particles under $10 \mathrm{mg} / \mathrm{m}^{3}$ (threshold limit value-short term exposure level or TLV-STEL). Baseline $\mathrm{FEV}_{1}$ was $85 \%$ predicted. ${ }^{7} \mathrm{FEV}_{1}$ did not fluctuate by more then $10 \%$ during the day. The $\mathrm{PC}_{20}$ for methacholine was $1.7 \mathrm{mg} / \mathrm{ml}$, confirming the mild bronchial hyperresponsiveness that had been seen a few years before. On the second day the patient was exposed to hydralazine for seven minutes with the same apparatus: no fluctuations in $\mathrm{FEV}_{1}$ of more than $10 \%$ were noticed during exposure or in the next few hours (a maximum increase in $\mathrm{FEV}_{1}$ of $5 \%$ was observed). On the third day the subject was exposed to hydralazine for progressively increasing periods totalling 30 minutes. He experienced a late asthmatic reaction with cough and shortness of breath. A maximal fall in $\mathrm{FEV}_{1}$ of $35.4 \%$ was recorded 270 minutes after exposure. Bronchoconstriction persisted for two hours. A bronchodilator was administered, with complete functional recovery. $\mathrm{FEV}_{1}$ remained below $90 \%$ of the baseline value for three days after the late reaction, but had returned to baseline by eight days after the inhalation test, at which time the $\mathrm{PC}_{20}$ was still low at $0.5 \mathrm{mg} / \mathrm{ml}^{6}{ }^{6} \mathrm{PC}_{20}$ was still reduced at 11 days $(0.44 \mathrm{mg} / \mathrm{ml})$ but had returned to baseline at 22 days $(1.3 \mathrm{mg} / \mathrm{ml})$.

Tests for IgE and IgG antibodies to hydralazine were performed by the radioallergosorbent test and the enzyme linked immunosorbent assay respectively by methods previously described. ${ }^{8}$ The results were negative.

\section{Discussion}

Our subject had a late reaction to inhalation challenges, suggesting that hydralazine can cause occupational asthma. The fact that he developed a late asthmatic reaction to a specific inhalation challenge with concentrations of particles below the TVL-STEL level makes an irritant reaction unlikely. The challenge was not blind and not repeated, so the possibility that some other agent-for example, aspirin-caused the reaction is a faint possibility. The fact that the reaction was prolonged in terms of changes in $\mathrm{FEV}_{1}$ (possible interval 3-8 days) and $\mathrm{PC}_{20}$ (possible

interval 11-22 days) makes this unlikely.
Address for correspondence Dr J-L Malo, Hôpital du Gouin, Montreal, Canad H4J 1 C5.

Accepted 20 June 1990 
FEV

(I)

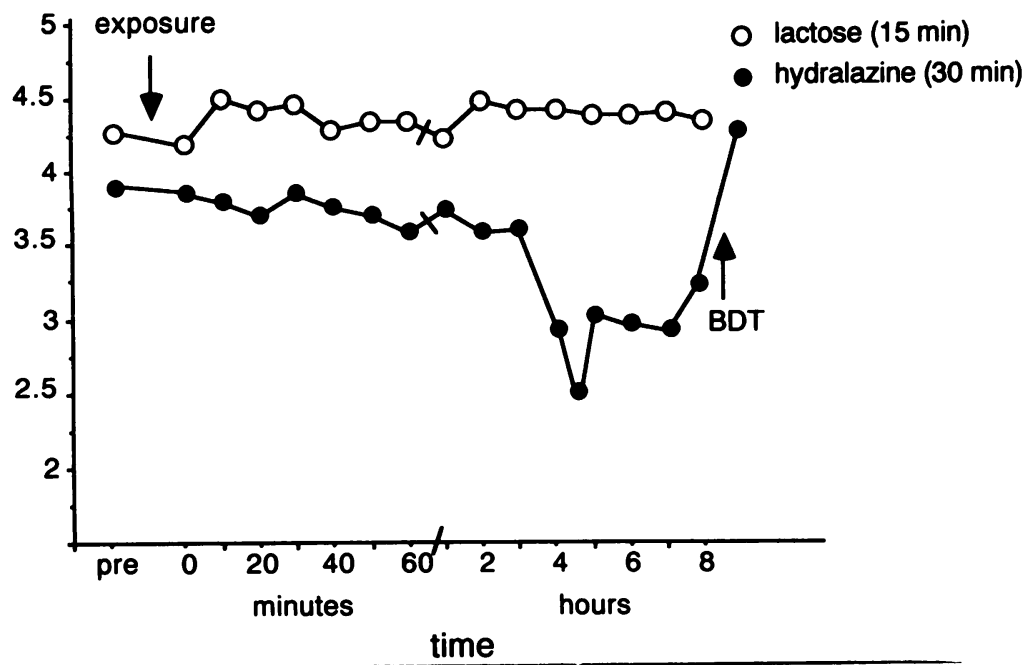

Changes in FEV, on the control day of exposure to lactose and on the last day of exposure to hydralazine. BDT-inhaled salbutamol (200 $\mu \mathrm{g})$.

No evidence for an immunological mechanism of the IgE or IgG type could be found. This is true of several pharmaceutical products that cause occupational asthma. ${ }^{12}$

Although no case of occupational asthma due to hydralazine has been reported to our knowledge, Fueki-without giving any objective evidence-mentioned that it could cause rhinitis. ${ }^{9}$

We wish to thank Katherine Tallman for reviewing the manuscript.

1 Chan-Yeung M, Lam S. Occupational asthma. Am Rev Respir Dis 1986;133:686-703.

2 Pauli G, Bessot JC, Dietemann-Molard A. Occupational asthma: investigations and aetiological factors. Clin Respir Physiol 1986;22:399-425.

3 Cartier A, Malo J-L, Dolovich J. Occupational asthma in nurses handling psyllium. Clin Allergy 1987;17:1-6.

4 Bardy JD, Malo J-L, Séguin P, Ghezzo H, Desjardins J, Dolovich J, Cartier A. Occupational asthma and IgE sensitization in a pharmaceutical company processing psyllium. Am Rev Respir Dis 1987;135:1033-8.

5 Malo J-L, Pineau L, Cartier A, Martin RR. Reference values of the provocative concentrations of methacholine that cause $6 \%$ and $20 \%$ changes in forced expiratory volume in one second in a normal population. Am Rev Respir Dis 1983;128:8-11.

6 Cloutier Y, Lagier F, Lemieux R, et al. New methodology for specific inhalation challenges with occupational agents in powder form. Eur Respir J 1989;2:769-77.

7 Knudson R, Lebowitz M, Holberg C, Burrows B. Changes in the normal maximum expiratory flow volume curve with growth and aging. Am Rev Respir Dis 1983;127: 725-34.

8 Dehaut P, Rachiele A, Martin RR, Malo J-L. Histamine dose-response curves in asthma: reproducibility and sensitivity of different indices to assess response. Thorax 1983;38:516-22.

9 Fueki R. Allergy in pharmacy. Farumacia 1970;6:364.

\section{BOOK NOTICES}

Respiratory Medicine. David C Flenley. 2nd ed. ( $\mathrm{Pp}$ 384; $£ 13.95$, paperback.) Edinburgh: Baillière Tindall, 1990. ISBN 0702013420.

The character of the author and his enormous grasp of respiratory medicine emerge clearly from the text of this second edition of his book, which was completed just a few weeks before his tragic death. The book is effectively a highly condensed comprehensive textbook of respiratory disease. The reader is spared no detail of the underlying science wherever this is relevant and the book acts as a convenient outline of the current state of knowledge in the subject as a whole. The book is highly suitable for the very best medical students and for those junior doctors who find themselves rotating through a respiratory medicine unit. It is a fund of information that even includes practical details such as drug dosesfor example, a complete guide on how to undertake and supervise anticoagulation. It is likely to be of most use to those who already have an understanding of the subject, and of the background elements of physiology, biochemistry, immunology, cell biology, etc, because the matter is in some places very compact and many of the sections tend to summarise rather than explain. A junior student might have some difficulty distinguishing what is basic and important from what is interesting but uncommon. It will be an excellent item for the ward bookshelf, a sound purchase for the MRCP candidate, and a convenient summary for those who need to organise their thoughts before undertaking formal teaching. The author was a true clinical scientist with a rigorous approach to any proposition before it was accepted as sound (until proved otherwise), but he was never dull or unbending. The humour of David Flenley pervades the sound clinical science. Things which he found amusing or extraordinary are relayed with relish in asides which are usually accorded an exclamation mark. Those who knew the author can easily imagine the rise of his penetrating voice, an equally penetrating look, and a broad grin.-RALB

Eosinophils, allergy and asthma. A B Kay. (Pp 163; $£ 25.95$.) Oxford: Blackwell, 1990. ISBN 0-632-028483.

This book, which is a summary of a meeting held in 1988, attempts to address some basic and applied aspects of eosinophil biology and in this it succeeds. What is more difficult is to find a role for this publication. It is a mixture of two types of chapter. Firstly, there are some excellent reviews, in particular the chapters by Capron, Kay, and Barnes, which review the immunoglobulin receptors, chemotactic factors, and pharmacology of the eosinophil and are very useful reference sources. The other 15 chapters review the research interest of the groups presenting the data, some of which represent up to date summaries of the work. Six of these chapters, however, do not contain any references more recent than 1988 and therefore fail to be useful for readers looking to this book for up to date information in those areas. Thus, although this book contains good reviews and some up to date research chapters, it is difficult to be certain of the audience it is aimed at as it does not fall into the role of textbook for the general library, or provide comprehensive, up to the minute research papers for the laboratory dedicated to studying the eosinophil or bronchial hyperreactivity.-RWF 